\title{
Intra-Articular ozone or Hyaluronic acid Injection in Patients with Knee Osteoarthritis
}

\author{
Muhammad Hamza Akram¹, Mohsan Nadeem Sheikh², Anwaar Khurshid ${ }^{3}$ \\ 1,2,3. House Officer Bahawal Victoria Hospital, Bahawalpur \\ Correspoundng Author:anwaarqme@gmail.com
}

\begin{abstract}
:
Objective: To compare the effect of ozone and hyaluronic acid for pain relief in patients of knee osteoarthritis. Study Design: Randomized clinical trial. Place of study: Study was conducted in the Pain Managment department of the Bahawal Victoria Hospital, Bahawalpur over a period of January, 2018 to January, 2019. Duration of study: study was completed in one year from February 2016 to February 2017. Methodology: A total of 200 patients were included in the study through non probability consecutive sampling and divided into two groups (A and B) through lottery method. Collected data was entered and analyzed by using SPSS version 24, mean and standard deviation were calculated for numerical data like age, and Visual Analog Scale (VAS scale) and Western Ontario and McMaster Universities Osteoarthritis Index (WOMAC score). Frequency and numbers were calculated for qualitative data like gender. Paired t-test and chi square test were applied to see significance of data, $p$-value less than or equal to 0.05 was considered as significant. Results: Mean age, BMI, WOMAC and VAS of ozone therapy's patients was $55.85 \pm 4.56$ years, $26.01 \pm 1.75 \mathrm{~kg} / \mathrm{m}^{2}, 42.23 \pm 7.30$ and $7.35 \pm 1.90$ respectively. Mean VAS, WOMAC pain, WOMAC stiffness, WOMAC function and WOMAC total of the HA therapy's (before) patients was $6.62 \pm 2.25,8.62 \pm 1.89,1.91 \pm 1.08,27.59 \pm 2.64$ and $37.67 \pm 4.06$ respectively. While, the mean VAS, WOMAC pain, WOMAC stiffness, WOMAC function and WOMAC total of the HA therapy's (after) patients was $3.08 \pm 1.68,2.97 \pm 1.21,1.0 \pm 0.48,13.36 \pm 2.39$ and $17.40 \pm 3.64$ respectively. According to paired sample $t$ test, the difference was statistically significant at $(\mathrm{p}<0.05)$.Conclusion: Results of our study concluded that ozone oxygen and hyalorunic acid is equally effective for relieve of pain in knee osteoarthritis. There was no significant difference among groups which shows that no drug have superiority on each other.
\end{abstract}

Keywords: Osteoarthritis, Intraarticular, Ozone, Hyalorunic acid, Pain.

DOI: $10.7176 / \mathrm{JMPB} / 52-17$

\section{Introduction:}

Osteoarthritis of knee joint is a degenerative disorder which becomes progressive and worse with the passage of time. Mechanical forces against the Joint are main cause of this disorder which leads into pain and reduction in joint movement ${ }^{1}$. Women with more than 50 years of age and obesity are more prone to disease than other population. Prevalence of OA varies region to region ${ }^{2}$. According to a survey conducted in $2009 \mathrm{OA}$ is the $4^{\text {th }}$ main cause of hospitalization and cost of its management is a huge burden on national economy $(\$ 42.3$ million per annum $)^{3}$.

Symptoms of OA are stiffness, pain, crepitus, swellingthat ends with deformity of joints. Clinical symptoms are very helpful for the diagnosis of OA. There is no definite treatment option available for OA, use of acetaminophen, non steroidal anti inflammatory drugs, topical patch, local use of cream is in practice to reduce pain and enhance the mobility ${ }^{4}$. Despite many non pharmacological treatments also available to reduce the symptoms including life style modifications, exercise, laser, assisted devices and some physical agent modalities. Surgery is a definite treatment available ${ }^{5}$.

Patients who are not eligible for surgery and pharmacological treatment various intra articular injections are also useful $^{6}$. Intra articular injection may include normal saline, platelet rich plasma, corticosteroids, phototherapy, dextrose, ozone and hyaluronic acid. A natural mucopolysaccharideis found in synovial joint which become diminished after development of OA. Effect of hyaluronic acid injection is anti inflammatory and viscoelastic and its use in OA pain is a topic of interest for new and non pharmacological research on OA treatment ${ }^{7,8}$.

Many studies and clinical trials were conducted on use of ozone and hyalorunic acid use in lambosacral disc herniation, shoulder disorders and failed back surgeries. Ozone also have good effects for relief of pain in traumatic meniscal injuries 9 . In study conducted Mishra et al efficiency of ozone was described as good when compared other steroid injections ${ }^{10}$. Its and efficacy is also proved. 
Number of studies was conducted on this topic worldwide but no local study available before; this study will fulfill the gap of local references. In this study our aim was to compare the effects of ozone therapy versus hyaluronic acid (HA) intra-articular injection in knee OA patients.

\section{Methodology:}

This randomized clinical trial was conducted in the Pain Managment department of the Bahawal Victoria Hospital, Bahawalpur over a period of January, 2018 to January, 2019. Written informed consent was obtained from participants and study was approved by hospital ethical committee. Patients with history of knee pain, pain aggravated on weight bearing, age limit 45 to 75 years, either gender and failed conservative treatment were enrolled in the study. Patients with history of trauma, injury to affected joint, abnormal coagulation and deranged blood count were excluded from the study.

Total number of patients was divided into two groups (A and B). Non probability consecutive sampling technique was adopted and sample size was calculated through WHO sample size calculator woth $95 \% \mathrm{Ci}$ and $80 \%$ study power. Group A patients were injected with ozone (10cc) in affected knee. Ozone was injected in combination of ozone and oxygen solution $(30 \mathrm{ug} / \mathrm{mL}$ concentration). Similarly in group B hylorunic acid was injected as $20 \mathrm{mg} / \mathrm{mL}$ solution of HA (molecular weight of 500-730 kDa). In both groups before injecting the experiment drugs $2 \mathrm{cc}$ of $2 \%$ of lidocaine was injected in knee in flexed position with the help of $22 \mathrm{G}$ needle. Injections were given on weekly basis till three weeks by and expert physician having 15 year experience in field of musculoskeletal injections.According to the need of patients' ice packing and rest upto 48 hours was advised to the patients after injection. Modifications in knee movements were also advised to patients along with some exercises like hamstring stretching and isometric quadriceps strengthening exercises.

Patients were evaluated before and after 6 months of treatment given with visual analogue score scale and WOMAC scoring system. Pain assessment was done by consultant who was blinded of study. WOMAC score was ranging from 0 to 4: 0 score means no pain and restriction, 1 score mean mild pain and restriction, 2 score means moderate pain and restriction, 3 score means severe pain and restriction and score 4 means very severe pain and restriction.

Collected data was entered and analyzed by using SPSS version 24, mean and standard deviation were calculated for numerical data like age, and VAS scale and WOMAC score. Frequency and numbers were calculated for qualitative data like gender. Student t-test and chi square test were applied to see significance of data, $\mathrm{P}$ value less than or equal to 0.05 was considered as significant.

\section{Results:}

A total number of 200 patients were enrolled in this study, both genders. The study patients were further divided into two equal groups i.e. Ozone and HA respectively. The mean age, BMI, WOMAC and VAS of ozone therapy's patients was $55.85 \pm 4.56$ years, $26.01 \pm 1.75 \mathrm{~kg} / \mathrm{m}^{2}, 42.23 \pm 7.30$ and $7.35 \pm 1.90$ respectively. OA grade II and III was observed as $(59 \%) n=59$ and $(41 \%) n=41$ respectively. There were $(56 \%) n=56$ males and $(44 \%) n=44$ females. While, the mean age, BMI, WOMAC and VAS of HA therapy's patients was $55.98 \pm 3.78$ years, $27.46 \pm 1.14 \mathrm{~kg} / \mathrm{m}^{2}, 38.35 \pm 4.14$ and $6.88 \pm 1.25$ respectively. OA grade II and III was observed as $(54 \%) \mathrm{n}=54$ and $(46 \%) n=46$ respectively. There were $(55 \%) n=55$ males and $(45 \%) n=45$ females. The difference was statistically significant of BMI $(\mathrm{p}=0.000)$, VAS $(\mathrm{p}=0.040)$ and WOMAC $(\mathrm{p}=0.000)$ with regards to groups. (Table. I).

The mean VAS, WOMAC pain, WOMAC stiffness, WOMAC function and WOMAC total of the ozone therapy's (before) patients was $6.91 \pm 2.49,9.24 \pm 1.54,2.28 \pm 1.0,28.19 \pm 5.07$ and $41.49 \pm 9.93$ respectively. While, The mean VAS, WOMAC pain, WOMAC stiffness, WOMAC function and WOMAC total of the ozone therapy's (after) patients was $2.75 \pm 1.92,3.10 \pm 1.45,1.30 \pm 0.95,15.68 \pm 4.10$ and $20.68 \pm 4.83$ respectively. According to paired sample $t$ test, the difference was statistically significant at $(\mathrm{p}<0.05)$. (Table. II).

The mean VAS, WOMAC pain, WOMAC stiffness, WOMAC function and WOMAC total of the HA therapy's (before) patients was $6.62 \pm 2.25,8.62 \pm 1.89,1.91 \pm 1.08,27.59 \pm 2.64$ and $37.67 \pm 4.06$ respectively. While, the mean VAS, WOMAC pain, WOMAC stiffness, WOMAC function and WOMAC total of the HA therapy's (after) patients was $3.08 \pm 1.68,2.97 \pm 1.21,1.0 \pm 0.48,13.36 \pm 2.39$ and $17.40 \pm 3.64$ respectively. According to paired sample $t$ test, the difference was statistically significant at $(\mathrm{p}<0.05)$. (Table. III). 
The mean VAS, WOMAC pain, WOMAC stiffness, WOMAC function and WOMAC total of the Ozone and HA therapy's (after) patients was presented in (Table IV). The difference was statistically insignificant.

\section{Table. I}

Demographic and baseline characteristics among both the groups

\begin{tabular}{|c|c|c|c|}
\hline Characteristics & $\begin{array}{l}\text { Ozone } \\
(n=100)\end{array}$ & $\begin{array}{c}\text { HA } \\
(n=100)\end{array}$ & $P$ value \\
\hline Age & $55.85 \pm 4.56$ & $55.98 \pm 3.78$ & 0.826 \\
\hline \multicolumn{4}{|l|}{ Gender } \\
\hline Male & $(56 \%) n=56$ & $(55 \%) n=55$ & \multirow[t]{3}{*}{0.090} \\
\hline Female & $(44 \%) n=44$ & $(45 \%) n=45$ & \\
\hline Total & $(100 \%) n=100$ & $(100 \%) n=100$ & \\
\hline BMI $\left(\mathrm{kg} / \mathrm{m}^{2}\right)$ & $26.01 \pm 1.75$ & $27.46 \pm 1.14$ & $<0.001$ \\
\hline WOMAC & $42.23 \pm 7.30$ & $38.35 \pm 4.14$ & $<0.001$ \\
\hline VAS & $7.35 \pm 1.90$ & $6.88 \pm 1.25$ & 0.040 \\
\hline \multicolumn{4}{|l|}{ OA Grade } \\
\hline II & $(59 \%) n=59$ & $(54 \%) n=54$ & \multirow[t]{3}{*}{0.476} \\
\hline III & $(41 \%) n=41$ & $(46 \%) n=46$ & \\
\hline Total & $(100 \%) n=100$ & $(100 \%) n=100$ & \\
\hline
\end{tabular}

Table. II

VAS and WOMAC scores of ozone group at the 6th month after injection

\begin{tabular}{|c|c|c|c|}
\hline Characteristics & $\begin{array}{c}\text { Ozone therapy } \\
\text { (before) } \\
(\mathbf{n = 1 0 0 )}\end{array}$ & $\begin{array}{c}\text { Ozone therapy } \\
\text { (after) } \\
(\mathbf{n = 1 0 0 )}\end{array}$ & P value \\
\hline VAS & $6.91 \pm 2.49$ & $2.75 \pm 1.92$ & $<\mathbf{0 . 0 0 1}$ \\
\hline WOMAC pain & $9.24 \pm 1.54$ & $3.10 \pm 1.45$ & $<\mathbf{0 . 0 0 1}$ \\
\hline WOMAC stiffness & $2.28 \pm 1.0$ & $1.30 \pm 0.95$ & $<\mathbf{0 . 0 0 1}$ \\
\hline WOMAC Function & $28.19 \pm 5.07$ & $15.68 \pm 4.10$ & $<\mathbf{0 . 0 0 1}$ \\
\hline WOMAC Total & $41.49 \pm 9.93$ & $20.68 \pm 4.83$ & $<\mathbf{0 . 0 0 1}$ \\
\hline
\end{tabular}


Table. III

VAS and WOMAC scores of HA group at the 6th month after injection

\begin{tabular}{|c|c|c|c|}
\hline Characteristics & $\begin{array}{c}\text { HA therapy } \\
\text { (Before) } \\
(n=100)\end{array}$ & $\begin{array}{c}\text { HA therapy } \\
\text { (after) } \\
(n=100)\end{array}$ & Test of Sig. \\
\hline VAS & $6.62 \pm 2.25$ & $3.08 \pm 1.68$ & $<0.001$ \\
\hline WOMAC pain & $8.62 \pm 1.89$ & $2.97 \pm 1.21$ & $<0.001$ \\
\hline WOMAC stiffness & $1.91 \pm 1.08$ & $1.0 \pm 0.48$ & $<0.001$ \\
\hline WOMAC Function & $27.59 \pm 2.64$ & $13.36 \pm 2.39$ & $<0.001$ \\
\hline WOMAC Total & $37.67 \pm 4.06$ & $17.40 \pm 3.64$ & $<0.001$ \\
\hline
\end{tabular}

Table. IV

\section{Difference of}

\begin{tabular}{|c|c|c|c|}
\hline Characteristics & $\begin{array}{c}\text { Ozone therapy } \\
(\text { after }) \\
(\mathbf{n = 1 0 0 )}\end{array}$ & $\begin{array}{c}\text { HA therapy } \\
(\text { after }) \\
(\mathbf{n = 1 0 0})\end{array}$ & P value \\
\hline VAS & $2.75 \pm 1.92$ & $3.08 \pm 1.68$ & $\mathbf{0 . 1 7 2}$ \\
\hline WOMAC pain & $3.10 \pm 1.45$ & $2.97 \pm 1.21$ & $\mathbf{0 . 8 9 4}$ \\
\hline WOMAC stiffness & $1.30 \pm 0.95$ & $1.0 \pm 0.48$ & $\mathbf{0 . 2 8 8}$ \\
\hline WOMAC Function & $15.68 \pm 4.10$ & $13.36 \pm 2.39$ & $\mathbf{0 . 8 2 7}$ \\
\hline WOMAC Total & $20.68 \pm 4.83$ & $17.40 \pm 3.64$ & $\mathbf{0 . 2 1 8}$ \\
\hline
\end{tabular}

\section{Discussion:}

In accordance with our results both drugs ozone and hyaluronic acid are equally effective no outcome variable have superiority over other. Some previous studies also document benefits of these both drugs. In a study conducted by Ahmed A. Al-Jaziri et al ${ }^{11}$ reported that ozone plus oxygen in combination have anti inflammatory and pain killing effects when administered in cases of osteoarthritis of spine and joints. Its mechanism of action and histological changes after intra articular injection is also proved.

In another study conducted by Seyman $\mathrm{D}$ et $\mathrm{al}^{12}$ reported that in cases of septic arthritis ozone injection is also beneficial. He demonstrated that ozone therapy is cost effective and its effective is now globally accepted. Rodriguez-Merchan et $\mathrm{al}^{13}$ conducted a study on this topic and use hyaluronic acid for intra articular medicine. He reported that use of hyaluronic acid recommended as five intra articular injections in a week before surgical intervention is a useful technique.

Raeissadat SA et $\mathrm{al}^{14}$ also conducted a randomized control trial between hyaluronic acid and ozone oxygen in patients of knee osteoarthritis and reported that both drugs are equally effective no one have superiority over other drug in any specific aspect. Six month follow up shows no superiority of both drugs on each other. 
Another trial was conducted in 2014 between ozone and hyalorunic acid by Momen Zadeh S et al ${ }^{15}$. Results of his study revealed that there was no mark able difference among groups on short follow up but a strong improvement was observed in both groups from baseline VAS score and WOMAC score. These results are compareable with our results. Another study was conducted in Turkey by Duymus TM et al ${ }^{16}$ and compared three groups ozone, HA and PRP and reported that HA have more better results as compared to PRP and ozone injection.

In another study conducted by Peter Jüni et $\mathrm{al}^{17}$ on comparison of Hylan and HA and observed some significant difference in hylan group but due to its cost and availability limits its use in our region. Similarly Kilincoglu V et a ${ }^{18}$ conducted a study in comparison of HA and platelet rich plasma and reported that PRP have lot of benefits over HA. Because plasma was drained from patients own blood so it has minimum risk of reaction and blood borne diseases. PRP is also more efficient than HA.

Kon $\mathrm{E}$ et $\mathrm{al}^{19}$ and Filardo $\mathrm{G}$ et $\mathrm{a}^{20}$ also conducted studies on comparison of PRP and HA Autologus PRP injections achieved more precise and controlled results as compare to HA and it is concluded that PRP is also cost effective with minimum complication chances when administered in knee OA. Results of these studies can be compared our results and study conclusion.

\section{Conclusion}

Results of our study concluded that ozone oxygen and hyalorunic acid is equally effective for relieve of pain in knee osteoarthritis. There was no significant difference among groups which shows that no drug have superiority on each other.

\section{Reference:}

1. Souza IF da S, de Oliveira Neta RS, Gazzola JM, de Souza MC. Elderly with knee osteoarthritis should perform nutritional assessment: integrative literature review. Einstein. 2017;15(2):226-232.

2. Cibulka MT, Bloom NJ, Enseki KR, Macdonald CW, Woehrle J, McDonough CM. Hip Pain and Mobility Deficits_-Hip Osteoarthritis: Revision 2017. J Orthop Sports Phys Ther. 2017;47(6):A1-A37.

3. Dai Wen-Li, Zhou Ai-Guo, Zhang Hua, Zhang Jian. Efficacy of Platelet-Rich Plasma in the Treatment of Knee Osteoarthritis: A Meta-analysis of Randomized Controlled Trials. Arthroscopy. 2017;33(3):659-670.

4. Fontaine C, Staumont-Sallé D, Hatron PY, Cotten A, Couturier C. The hand in systemic diseases other than rheumatoid arthritisLa main dans les maladies systémiques autres que la polyarthrite rhumatoïde. Chir Main. 2014;33(3):155-73.

5. Bega D, Malkani R. Alternative treatment of restless legs syndrome: an overview of the evidence for mind-body interventions, lifestyle interventions, and neutraceuticals. Sleep Med. 2016;17:99-105.

6. Pitsouni E, Grigoriadis T, Falagas ME, Salvatore S, Athanasiou S. Laser therapy for the genitourinary syndrome of menopause. A systematic review and meta-analysis. Maturitas. 2017;103:78-88.

7. Matzkin EG, Curry EJ, Kong Q, Rogers MJ, Henry M, Smith EL. Efficacy and Treatment Response of Intra-articular Corticosteroid Injections in Patients With Symptomatic Knee Osteoarthritis. J Am Acad Orthop Surg. 2017;25(10):703-714.

8. Simon TM, Jackson DW. Articular Cartilage: Injury Pathways and Treatment Options. Sports Med Arthrosc Rev. 2006;14(3):146-54.

9. Kroon, F.P.B., Rubio, R., Schoones, J.W. Intra-Articular Therapies in the Treatment of Hand Osteoarthritis: A Systematic Literature Review. Drugs Aging. 2016;33:p119.

10. Mishra SK, Pramanik R, Das P, et al. Role of intra-articular ozone in osteo-arthritis of knee for functional and symptomatic improvement. Ind J Phys Med Rehabil. 2011;22(2):65-69.

11. Al-Jaziri AA, Mahmoodi SM. Pain killing effect of ozone-oxygen injec- tion on spine and joint osteoarthritis. Saudi Med J. 2008;29(4):553-557.

12. Seyman D, Ozen NS, Inan D, Ongut G, Ogunc D. Pseudomonas aeru- ginosa septic arthritis of knee after intra-articular ozone injection. New Microbiologica. 2012;35(3):345-348. 
13. 29. Rodriguez-Merchan EC. Intra-articular injections of hyaluronic acid and other drugs in the knee joint. HSS J. 2013;9(2):180-182.

14. Raeissadat SA, Babaee M, Rayegani SM, et al. An overview of platelet products (PRP, PRGF, PRF, etc.) in the Iranian studies. Futur Sci OA. 2017;3(4):FSO231.

15. Momen Zadeh S, Pour Farrokh M, Hashemi M, Barikani A. Comparison of intra-articular oxygenozone and hyaluronic acid prolotherapy on pain and disability of osteoarthritis patients. Res Med. 2014;38(1):32-36.

16. Duymus TM, Mutlu S, Dernek B, Komur B, Aydogmus S, Nur Kesiktas F. Choice of intra-articular injection in treatment of knee osteoarthritis: platelet-rich plasma, hyaluronic acid or ozone options. Knee Surg Sports Traumatol Arthrosc. 2016;25(2):485-492.

17. Juni $P$, Reichenbach $S$, Trelle S, et al. Efficacy and safety of intraarticular hylan or hyaluronic acids for osteoarthritis of the knee: A randomized controlled trial. Arthritis Rheum. 2007;56(11):3610-3619.

18. Kilincoglu V, Yeter A, Servet A, Kangal M, Yildirim M. Short term results comparison of intraarticular platelet-rich plasma (PRP) and hyaluronic acid (HA) applications in early stage of knee osteoarthritis. Int J Clin Exp Med. 2015;8(10):18807-18812.

19. Kon E, Mandelbaum B, Buda R, et al. Platelet-rich plasma intra-articular injection versus hyaluronic acid viscosupplementation as treatments for cartilage pathology: From early degeneration to osteoarthritis. Arthroscopy. 2011;27(11):1490-1501.

20. Filardo G, Kon E, Longo UG, Madry H, Marchettini P, Marmotti A. Non-surgical treatments for the management of early osteoarthritis. Knee Surg Sports Traumatol Arthrosc. 2016;24(6):1775-85. 